\title{
Características fisiológicas, nutricionais e rendimento de forrageiras fertigadas com água residuária de bovinocultura
}

\author{
Virgílio J. T. Ethal1', Paulo A. Ferreira², Odilion G. Pereira ${ }^{3} \&$ Antônio T. de Matos $^{2}$
}

\begin{abstract}
RESUMO
A disposição de águas residuárias no sistema solo-planta, feita sem critérios agronômico e ambiental, pode causar problemas de contaminação do solo, das águas superficiais e subterrâneas e toxicidade às plantas. Com o objetivo de avaliar os efeitos da fertigação com água residuária de bovinocultura (ARB) sobre as características fisiológicas, nutricionais e de produtividade do capim-Tifton 85 (Cynodon spp.) e da aveia-preta (Avena strigosa Schreb), realizou-se um experimento utilizando-se quatro taxas de aplicação da ARB $\left(25,50,75\right.$ e $100 \mathrm{~kg} \mathrm{ha}^{-1}$ de K) em condições de lisímetros de drenagem em casa de vegetação. As variáveis fisiológicas, nutricionais e de rendimento avaliadas foram: taxa fotossintética, taxa transpiratória, condutância estomática, teor de clorofila na folha, rendimento forrageiro, teor de proteína bruta (PB) e teor de nutrientes na matéria seca ( $\mathrm{P}, \mathrm{K}, \mathrm{Ca}, \mathrm{Mg}, \mathrm{Na}, \mathrm{Zn}$ e $\mathrm{Cu})$. $\mathrm{O}$ s resultados indicaram que a utilização da $\mathrm{ARB}$ não causou estresse osmótico nem toxicidade pelos elementos químicos analisados mas propiciou absorção de nutrientes e rendimento forrageiro em níveis próximos aos recomendados podendo, portanto, substituir parcialmente a adubação mineral para o cultivo dessas forrageiras.
\end{abstract}

Palavras-chave: variáveis fisiológicas, composição mineral, capim-Tifton 85, aveia-preta

\section{Physiological, nutritional and yield characteristics of forages fertigated with cattle wastewater}

\begin{abstract}
When accomplished without agronomic and environmental criteria, the disposal of the wastewaters in the soil-plant system can cause contamination problems in the soil, to both surface and subsurface waters as well as toxicity to the plants. This study was carried out to evaluate the effects from the fertigation with cattle wastewater (ARB) on the physiologic, nutritional and yield characteristics of the Tifton 85 grass (Cynodon spp.) and the black oat (Avena strigosa Schreb). The experiment was performed with four ARB application rates $\left(25,50,75\right.$ and $100 \mathrm{~kg} \mathrm{ha}^{-1}$ of $\mathrm{K}$ ) using drainage lysimeters under greenhouse conditions. The following physiologic, nutritional and yield variables were evaluated: photosynthetic rate, transpiration rate, stomatic conductance, leaf chlorophyll content, forage productivity, crude protein content (PB) and content of nutrients in the dry matter ( $\mathrm{P}, \mathrm{K}, \mathrm{Ca}, \mathrm{Mg}, \mathrm{Na}, \mathrm{Zn}$ and $\mathrm{Cu}$ ). According to the results, the following conclusions were drawn: the use of ARB caused no stress due to the osmotic effect neither direct toxicity by the chemical elements analysised, besides providing nutrient absorption and forage yield at levels close to the recommended ones. Therefore, this ARB can partially substitute the mineral fertilization in cropping these forages.
\end{abstract}

Key words physiologic variables, mineral composition, Tifton 85 grass, black oat 


\section{INTRODUÇÃO}

A disposição de águas residuárias agroindustriais e domésticas no solo é uma técnica interessante, principalmente em condições de clima tropical e com disponibilidade de áreas, como é o caso do Brasil. Esta técnica se baseia na capacidade depuradora do sistema solo-planta, que utiliza mecanismos físicos, químicos e biológicos de remoção dos poluentes contidos nas águas residuárias.

Estudos realizados em diversos países demonstraram que a produtividade agrícola aumenta significativamente em áreas fertigadas com águas residuárias, desde que estas sejam adequadamente manejadas. A maioria dos estudos está relacionada com a utilização de águas residuárias de origem doméstica e seus efeitos sobre o rendimento de massa seca e/ ou proteína bruta em espécies forrageiras (Adekalu \& Okunade, 2002; Grattan et al., 2004; Mohammad \& Ayadi, 2004).

No Brasil avaliou-se, através de alguns trabalhos, a aplicação de águas residuárias em sistemas cultivados com gramíneas forrageiras (Fonseca et al., 2007; McLaughlin et al., 2004; Queiroz et al., 2004; Matos et al., 2003) e se constatou que essas águas podem substituir eficientemente a água limpa, proporcionando benefícios econômicos, com aumento da qualidade e rendimento da forragem, além de ser uma opção interessante do ponto de vista ambiental.

Queiroz et al. (2004) avaliaram o comportamento de quatro gramíneas forrageiras (Quicuio da Amazônia, Braquiária, Tifton 85 e Coastcross) em rampas de tratamento com água residuária de suinocultura. Os conteúdos de proteína bruta foram, em todos os capins, superiores quando receberam água residuária de suinocultura em relação à água da rede de abastecimento; os autores afirmam, ainda, que esses resultados podem ser, também, usados para avaliação da capacidade das gramíneas forrageiras em extrair nitrogênio do solo.

Por outro lado, existem efeitos negativos da utilização de águas residuárias, sobretudo aqueles causados pela alta concentração de sais existentes nessas águas. O aumento da concentração de sais no solo, causado pela aplicação de águas residuárias, faz com que as plantas necessitem de ajustamento osmótico a fim de manter o fluxo de água no sentido solofolha. O efeito da redução do componente osmótico do potencial da água no solo é similar ao de um déficit hídrico, consequente da depleção de água no solo para a maioria das plantas (Taiz \& Zeiger, 2004).

O referencial para definição das taxas de aplicação não deve ser lâminas calculadas em função da evapotranspiração da cultura e, sim, da capacidade do sistema solo-planta em absorver o resíduo aplicado sem comprometer a qualidade do solo, da planta nem das águas subterrâneas. Em geral, os teores de nitrogênio, elementos fitotóxicos, metais pesados e a salinidade, têm sido utilizados como referenciais na determinação da lâmina a ser aplicada na fertigação, devendo-se tomar por base o componente de maior concentração na água.

Na escolha de plantas forrageiras para fins de aplicação de águas residuárias por disposição no solo, deve-se preferir as perenes, alta capacidade de extração de nutrientes e produção de matéria seca, que permitam cortes frequentes e sucessivos ao longo da maior parte do ano, que cubram bem o solo e sejam palatáveis aos animais; outras características desejáveis, são: adaptar-se às condições de clima e solo locais, baixa susceptibilidade a pragas e doenças e tolerância à salinidade e toxicidade a íons específicos.

Nesse contexto e tendo em vista que a produção de água residuária de bovinocultura é contínua ao longo do ano, optou-se por trabalhar com o capim-Tifton 85 (Cynodon spp), no período de primavera-verão e com a aveia-preta (Avena strigosa Schreb), em sobressemeadura nas entrelinhas do Tifton, no período de outono-inverno.

Objetivou-se, neste trabalho, avaliar os efeitos nas características fisiológicas, nutricionais e de produtividade do capim-Tifton 85 (Cynodon spp.) e da aveia-preta (Avena strigosa Schreb), fertigados com água residuária de bovinocultura em quatro taxas de aplicação, em condições de lisímetros de drenagem em casa de vegetação.

\section{MATERIAL E MÉTODOS}

O trabalho foi conduzido em 20 lisímetros de drenagem de 1,0 m de largura, 1,40 m de comprimento e 0,80 m de profundidade, construídos em ambiente protegido, no campus da Universidade Federal de Viçosa, Viçosa, MG, com coordenadas geográficas de $20^{\circ} 45^{\prime}$ de latitude Sul, $42^{\circ} 45^{\prime}$ de longitude Oeste e altitude de $651 \mathrm{~m}$.

A espessura do perfil do solo nos lisímetros era de $0,70 \mathrm{~m}$ e o solo utilizado foi coletado no perfil de um Argissolo Vermelho Escuro Eutrófico Tb. O delineamento experimental foi inteiramente casualizado com cinco tratamentos e quatro repetições. Tendo em vista a recomendação de adubação potássica para manutenção de pastagens (CFSEMG, 1999) adotaram-se quatro taxas de aplicação da água residuária, com base na concentração de potássio (25, 50, 75 e $\left.100 \mathrm{~kg} \mathrm{ha}^{-1}\right)$ por ciclo de cultivo, além de um tratamento com água limpa e adubação mineral.

O sistema para o preparo e distribuição das misturas de águas referentes aos cinco tratamentos, constituiu-se de cinco reservatórios com capacidade para $250 \mathrm{~L}$, providos de saída controlada por registro e interligados a uma motobomba. As misturas eram aplicadas manualmente sobre o solo, com o auxílio de uma mangueira equipada com hidrômetro e frequência de aplicação semanal. A água residuária utilizada foi coletada no estábulo do Setor de Bovinocultura de Leite do Departamento de Zootecnia da UFV.

A instalação do experimento ocorreu na primeira quinzena do mês de outubro de 2006, quando as mudas de capimTifton 85 foram transplantadas; após setenta dias realizouse um corte de uniformização em todas as parcelas, quando se iniciaram os tratamentos; no total, foram três ciclos de produção do capim-Tifton 85, no período de 15/12/2006 a 14/05/2007 e um ciclo de Tifton 85 em consórcio com aveiapreta, sobressemeada nas entrelinhas, em densidade correspondente a $70 \mathrm{~kg} \mathrm{ha}^{-1}$ de sementes viáveis, no período de 15/ 05 a 06/08/2007. 
As variáveis fisiológicas, nutricionais e de rendimento avaliadas, foram as taxas fotossintética e transpiratória, os teores de clorofila na folha, proteína bruta $(\mathrm{PB})$ e nutrientes (P, K, Ca, Mg, Na, Zn e Cu), condutância estomática e rendimento forrageiro; os cortes foram efetuados a cada 49 dias e, na semana anterior a cada corte, avaliaram-se os teores de clorofila na folha com o auxílio de um clorofilômetro; as leituras foram feitas na terceira folha completamente desenvolvida, em trinta plantas por parcela, entre nove e dez horas da manhã.

Realizaram-se as medições da taxa fotossintética, condutância estomática e taxa transpiratória na terceira folha de uma planta representativa, em cada unidade experimental, no dia anterior ao corte, utilizando-se um analisador portátil de $\mathrm{CO}_{2}$ a infra-vermelho (IRGA), com intensidade luminosa artificial de $1000 \mu$ moles $\mathrm{m}^{-2} \mathrm{~s}^{-1}$.

O material usado para estimativa do rendimento forrageiro foi colhido em área útil de $0,6 \mathrm{~m}^{2}$; o corte foi efetuado a 0,05 m de altura da superfície do solo, com auxílio de um cutelo; pesou-se o material coletado obtendo-se a produção de massa verde na área útil. Uma subamostra foi separada, pesada e submetida a pré-secagem em estufa de ventilação forçada a $65^{\circ} \mathrm{C}$, durante $72 \mathrm{~h}$; em seguida, o material foi moído em moinho tipo "Willey”, com peneira de 30 mesh, acondicionado em recipientes plásticos e encaminhado ao Laboratório de Nutrição Animal do Departamento de Zootecnia para as análises de N, P, K, Na, Ca, Mg, Zn e Cu, conforme Silva \& Queiroz (2002); para quantificação da matéria seca, o material foi secado em estufa, a $105^{\circ} \mathrm{C}$.

Os resultados foram submetidos às análises de variância e de regressão. A análise de variância para as características: altura, relação lâmina/colmo, composição químico-bromatológica e extração de minerais referentes ao capim-Tifton 85 foi feita considerando-se o esquema de parcelas subdivididas, com os tratamentos na parcela e os cortes, na subparcela. Os modelos de regressão foram escolhidos com base na significância dos coeficientes de regressão, utilizando-se o teste "t" e adotando-se $\alpha$ de até $10 \%$, no fenômeno em estudo e no coeficiente de determinação $\left(\mathrm{r}^{2}\right)$ calculado para médias de tratamento, conforme a Eq. 1:

$$
\mathrm{R}^{2}=\frac{\mathrm{SQRg}}{\mathrm{SQTrat}}
$$

em que:

SQRg - soma de quadrados da regressão

SQTrat - soma de quadrados de tratamento

\section{RESULTADOS E DISCUSSÃO}

\section{Aporte de nutrientes}

Com base nas concentrações de nutrientes presentes na ARB no início de cada ciclo e nos volumes aplicados por ciclo, estimou-se o aporte de nutrientes aos lisímetros pela água residuária por ciclo e tratamento (Tabela 1).

\section{Taxas fotossintética, transpiratória e condutância estomática}

As variáveis fisiológicas não apresentaram respostas significativas em função dos tratamentos para o capim-Tifton 85, considerando-se a média dos três ciclos de produção, enquanto para a aveia-preta as três variáveis responderam significativamente aos tratamentos, apresentando médias de tratamento estatisticamente iguais ou superiores à testemunha (Tabela 2).

A análise de regressão dos dados da aveia-preta revelou que a taxa fotossintética aumentou linearmente em resposta

Tabela 1. Aporte de nutrientes via água residuária de bovinocultura (ARB) durante o experimento

\begin{tabular}{|c|c|c|c|c|c|c|c|c|c|}
\hline \multirow{2}{*}{ Ciclo } & \multirow{2}{*}{ Tratamento } & $\mathrm{N}$-total & $\mathbf{P}$ & $K$ & $\mathrm{Ca}$ & $\mathrm{Mg}$ & $\mathrm{Na}$ & $\mathrm{Zn}$ & $\mathrm{Cu}$ \\
\hline & & \multicolumn{8}{|c|}{$\mathrm{kg} \mathrm{ha}^{-1}$} \\
\hline \multirow{4}{*}{ I } & 25 & 58,1 & 14,5 & 25,4 & 7,5 & 6,5 & 7,3 & 0,21 & 0,14 \\
\hline & 50 & 116,3 & 28,9 & 50,8 & 15,0 & 13,0 & 14,6 & 0,42 & 0,29 \\
\hline & 75 & 174,4 & 43,4 & 76,2 & 22,5 & 19,5 & 21,9 & 0,63 & 0,43 \\
\hline & 100 & 232,6 & 57,9 & 101,6 & 30,0 & 26,0 & 29,2 & 0,84 & 0,58 \\
\hline \multirow{3}{*}{ II } & 25 & 38,0 & 7,3 & 25,1 & 12,3 & 0,0 & 4,6 & 0,29 & 0,15 \\
\hline & 75 & 114,0 & 22,0 & 75,2 & 37,0 & 0,0 & 13,9 & 0,86 & 0,44 \\
\hline & 100 & 152,0 & 29,3 & 100,3 & 49,3 & 0,0 & 18,5 & 1,15 & 0,59 \\
\hline \multirow{4}{*}{ III } & 25 & 46,7 & 5,8 & 25,0 & 9,7 & 0,0 & 7,0 & 0,17 & 0,05 \\
\hline & 50 & 93,3 & 11,6 & 50,0 & 19,5 & 0,0 & 13,9 & 0,33 & 0,11 \\
\hline & 75 & 140,0 & 17,4 & 75,0 & 29,2 & 0,0 & 20,9 & 0,50 & 0,16 \\
\hline & 100 & 186,6 & 23,3 & 100,0 & 39,0 & 0,0 & 27,9 & 0,66 & 0,21 \\
\hline \multirow{3}{*}{ IV } & 25 & 47,6 & 5,5 & 25,1 & 3,9 & 0,0 & 6,3 & 0,11 & 0,04 \\
\hline & 75 & 142,7 & 16,4 & 75,2 & 11,8 & 0,0 & 18,8 & 0,34 & 0,12 \\
\hline & 100 & 190,3 & 21,8 & 100,3 & 15,8 & 0,0 & 25,0 & 0,46 & 0,16 \\
\hline \multirow{4}{*}{ Total } & 25 & 190,4 & 33,1 & 100,5 & 33,5 & 6,5 & 25,1 & 0,88 & 0,38 \\
\hline & 50 & 380,7 & 66,1 & 201,1 & 67,0 & 13,0 & 50,3 & 1,61 & 0,78 \\
\hline & 75 & 571,1 & 99,2 & 301,6 & 100,5 & 19,5 & 75,4 & 2,33 & 1,15 \\
\hline & 100 & 761,5 & 132,3 & 402,2 & 134,0 & 26,0 & 100,6 & 3,08 & 1,54 \\
\hline
\end{tabular}


Tabela 2. Taxa fotossintética (A), taxa transpiratória (E) e condutância estomática (gs) de plantas de capim-Tifton 85 e aveia-preta, em função das taxas de aplicação da ARB

\begin{tabular}{cccccc}
\hline \multirow{2}{*}{ Forrageira } & \multicolumn{5}{c}{ Tratamentos } \\
\cline { 2 - 6 } & Testemunha & $\mathbf{2 5}$ & $\mathbf{5 0}$ & $\mathbf{7 5}$ & $\mathbf{1 0 0}$ \\
Tifton 85 & 9,482 & 12,401 & 13,686 & 12,633 & 12,524 \\
Aveia-preta & 6,766 & 7,278 & $9,624^{*}$ & $9,456^{\star}$ & $11,335^{\star}$ \\
\hline \multicolumn{5}{c}{$\mathrm{E}\left(\mathrm{mmol} \mathrm{m}^{-2} \mathrm{~s}^{-1} \mathrm{de} \mathrm{H}_{2} 0\right)$} \\
Tifton 85 & 1,913 & 1,879 & 2,299 & 1,915 & 1,924 \\
Aveia-preta & 2,901 & 3,433 & $3,916^{*}$ & $3,611^{*}$ & $3,620^{*}$ \\
\hline \multicolumn{7}{c}{$\mathrm{Gs}\left(\mathrm{mol} \mathrm{m}^{-2} \mathrm{~s}^{-1} \mathrm{de}_{2} \mathrm{CO}_{2}\right)$} \\
Tifton 85 & 0,047 & 0,051 & 0,058 & 0,043 & 0,043 \\
Aveia-preta & 0,107 & 0,130 & $0,179^{*}$ & $0,169^{\star}$ & $0,148^{*}$ \\
\hline
\end{tabular}

Valores seguidos de asterisco, na linha, diferem estatisticamente em nível de $5 \%$ de probabilidade da testemunha, pelo teste de Dunnett

às taxas crescentes de aplicação da ARB, enquanto a condutância estomática variou conforme o modelo quadrático, mostrando tendência de redução para taxas de aplicação acima de $60 \mathrm{~kg} \mathrm{ha}^{-1}$ de K na ARB (Figura 1).

Esses resultados indicam fechamento estomático em razão do possível efeito osmótico causado pelas taxas de aplicação superiores a $60 \mathrm{~kg} \mathrm{ha}^{-1}$ de $\mathrm{K}$ na ARB porém as taxas fotossintéticas apresentaram incremento, não caracterizando estresse.

De acordo com Taiz \& Zeiger (2004), o efeito da redução da condutância estomática pode ser eliminado pelo alto suprimento de $\mathrm{CO}_{2}$ que manteria a taxa fotossintética em níveis adequados, o que é coerente com o comportamento observado no presente estudo, visto que o experimento foi realizado em condições de casa de vegetação.
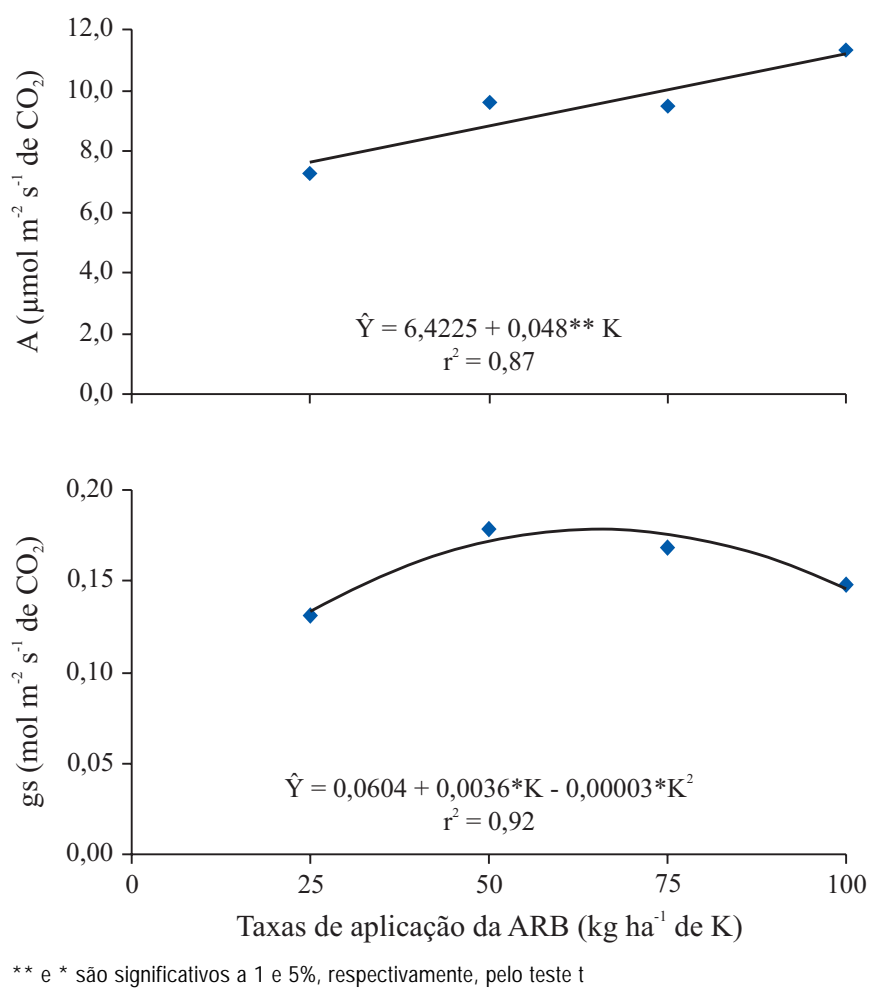

Figura 1. Taxa fotossintética (A) e condutância estomática (gs) da aveia-preta em função das taxas de aplicação da ARB
Para as taxas transpiratórias da aveia e do Tifton 85 e para a taxa fotossintética e condutância estomática do Tifton 85, os modelos de regressão não apresentaram significância estatística, indicando que as plantas não sofreram estresse devido ao efeito osmótico ou por toxicidade a íons presentes na ARB. Parida \& Bandhu (2005) relataram que em altas concentrações salinas a eficiência fotossintética de diversas culturas pode ser afetada de forma significativa mas, no caso, se os efeitos osmóticos e de íons-específicos decorrentes da absorção de sais presentes na ARB excedessem o nível de tolerância das plantas, a fotossíntese seria afetada tanto pelo fechamento estomático quanto pelo efeito do sal nos cloroplastos (Larcher, 2000; Taiz \& Zeiger, 2004).

\section{Índice SPAD}

A análise de variância revelou efeito significativo $(\mathrm{p}<0,05)$ para as leituras de clorofila realizadas com o Chlorophyll Meter SPAD-502 nas lâminas de folhas do capim-Tifton 85 e da aveia-preta, em função dos tratamentos. Conforme apresentado na Tabela 3, em ambas as forrageiras a taxa de aplicação da ARB correspondente à maior dose de $\mathrm{K}$ apresentou valores máximos de leitura SPAD, indicando que este tratamento propiciou maior teor de clorofila na folha em função, principalmente, do maior aporte de nitrogênio ao solo.

Tabela 3. Índice SPAD de plantas de capim-Tifton 85 e aveia-preta, em função das doses de $K$ na ARB

\begin{tabular}{cclcll}
\hline \multirow{2}{*}{ Forrageiras } & \multicolumn{5}{c}{ Tratamentos } \\
\cline { 2 - 6 } Testemunha & $\mathbf{2 5}$ & $\mathbf{5 0}$ & $\mathbf{7 5}$ & $\mathbf{1 0 0}$ \\
Tifton 85 & 24,1 & 23,6 & 24,6 & 23,9 & $25,8^{*}$ \\
Aveia-preta & 29,9 & $26,2^{*}$ & 31,7 & $34,2^{*}$ & $39,6^{*}$ \\
\hline
\end{tabular}

Valores seguidos de asterisco na linha, diferem estatisticamente, em nível de $5 \%$ de probabilidade da testemunha, pelo teste de Dunnett

Esses resultados estão coerentes com os relatados por Bullock \& Anderson (1998), ao afirmarem que, a medida em que a disponibilidade de nitrogênio no solo aumenta mais clorofila é produzida nas folhas das plantas, que respondem com o aumento da intensidade da coloração verde. Por outro lado, o desbotamento dos pigmentos foliares estaria diretamente relacionado com a degradação do conteúdo de clorofila, conseqüente do efeito da salinidade (Lutts et al., 1996; Chen et al., 1999). Rosa-Ibarra \& Maiti (1995) observaram que concentrações elevadas de $\mathrm{NaCl}$ podem aumentar a degradação de clorofilas via atividade clorofilase ou diminuir a sua síntese, em virtude da competição por nitrogênio com outros compostos, como a prolina.

A variação no valor das unidades SPAD foi mais bem representada pelo modelo linear, para ambas as forrageiras (Tabelas 4 e 5); esses resultados diferem daqueles apresentados por Premazzi et al. (2003), que avaliaram o efeito de doses de $\mathrm{N}$ sobre o valor SPAD em capim-Tifton 85 e encontraram modelos de resposta quadráticos.

\section{Rendimento acumulado de matéria seca na parte aérea}

A análise de variância do rendimento de matéria seca indica que houve efeito significativo dos tratamentos 
( $p<0,01)$ nas duas forrageiras. Observa-se, na Tabela 6, que para o Tifton 85 o tratamento correspondente à maior taxa de aplicação da ARB, proporcionou rendimento estatisticamente igual ao da testemunha e superior aos demais. Por outro lado, para a aveia-preta apenas os tratamentos 25 e 50 diferiram da testemunha; entretanto, quando se considera o rendimento total (tifton + aveia), apenas o tratamento 100 foi igual à testemunha; este fato demonstra que uma taxa maior de aplicação da ARB pode substituir a adubação mineral em relação à matéria seca.

Tabela 4. Equações ajustadas para as variáveis fisiológicas, nutricionais e de rendimento do capim-Tifton 85

\begin{tabular}{llc}
\hline \multicolumn{1}{c}{ Variável } & \multicolumn{1}{c}{$\quad$ Equações ajustadas } & $\mathbf{R}^{2}$ \\
Índice SPAD & $\hat{y}=22,9+0,025^{* * K} \mathrm{~K}$ & 0,61 \\
Rend. Mat. Seca & $\hat{y}=4951,3+45,94^{* *} \mathrm{~K}$ & 0,91 \\
Proteína Bruta & $\hat{y}=7,842+0,03^{* *} \mathrm{~K}$ & 0,99 \\
$\mathrm{~K}$ & $\hat{y}=1,356+0,005^{* *} \mathrm{~K}$ & 0,96 \\
$\mathrm{Ca}$ & $\hat{y}=0,522-0,0014^{* * K}$ & 0,93 \\
$\mathrm{Na}$ & $\hat{y}=0,067-0,0008^{* *} \mathrm{~K}+0,000005^{* *} \mathrm{~K}^{2}$ & 0,99 \\
$\mathrm{Zn}$ & $\hat{y}=39,4-0,205^{* *} \mathrm{~K}+0,0013^{*} \mathrm{~K}^{2}$ & 0,93 \\
\hline${ }^{*} \mathrm{e}^{* *}$ são coeficientes significativos a 5 e $1 \%$ de probabilidade, respectivamente, pelo teste $\mathrm{t}$
\end{tabular}

Tabela 5. Equações ajustadas para as variáveis fisiológicas, nutricionais e de rendimento da aveia-preta

\begin{tabular}{|c|c|c|}
\hline Variável & Equações ajustadas & $\mathbf{R}^{2}$ \\
\hline Índice SPAD & $\hat{y}=22,3+0,17^{\star *} K$ & 0,98 \\
\hline Rend. Mat. Seca & $\hat{y}=-191,05+29,41^{\star \star} K$ & 0,98 \\
\hline Proteína Bruta & $\hat{y}=8,475+0,027^{* \star K}$ & 0,97 \\
\hline K & $\hat{y}=1,399+0,008 * * K$ & 0,99 \\
\hline $\mathrm{Na}$ & $\hat{y}=0,1997-0,0022^{\star *} K+0,00003^{* *} K^{2}$ & 0,98 \\
\hline $\mathrm{Cu}$ & $\hat{y}=2,74-0,0081 * * K$ & 0,57 \\
\hline
\end{tabular}

Tabela 6. Rendimento de matéria seca por planta e total ( $\mathrm{kg} \mathrm{ha}^{-1}$ ) das forrageiras em função das taxas de aplicação da ARB

\begin{tabular}{ccrccc}
\hline \multirow{2}{*}{ Forrageira } & \multicolumn{5}{c}{ Tratamentos } \\
\cline { 2 - 6 } & Testemunha & \multicolumn{1}{c}{$\mathbf{5}$} & $\mathbf{5 0}$ & $\mathbf{7 5}$ & $\mathbf{1 0 0}$ \\
Tifton 85 & $11.162,9$ & $6.385,4^{*}$ & $7.112,2^{*}$ & $7.811,4^{*}$ & $9.980,4$ \\
Aveia-preta & $2.384,7$ & $650,2^{*}$ & $1.177,0^{*}$ & $1.901,8$ & $2.859,5$ \\
Total & $13.547,6$ & $7.035,6^{*}$ & $8.289,2^{*}$ & $9.713,2^{*}$ & $12.840,0$ \\
\hline
\end{tabular}

Valores seguidos de asterisco na linha diferem estatisticamente em nível de $5 \%$ de probabilidade da testemunha, pelo teste de Dunnett

Resultados semelhantes de rendimento de matéria seca, em função da aplicação de águas residuárias no solo, têm sido verificados por vários autores (Grattan et al., 2004; Mohammad \& Ayadi, 2004; Adekalu \& Okunade, 2002).

Martim (1997), avaliando doses de nitrogênio e potássio para a produção dos capins Tifton 85 e Coastcross 1, encontrou modelos de resposta linear positiva para produção de matéria seca, em função dos níveis de N e K, porém o efeito do potássio só foi significativo nos segundo e terceiro cortes.

Os valores de rendimento forrageiro encontrados para a aveia-preta no presente trabalho, são inferiores aos verificados por Prado et al. (2006) e Matos et al. (2003; 2005). Es- ses menores rendimentos se devem, provavelmente, ao fato da aveia-preta estar consorciada ao capim-Tifton 85 e às condições ambientais.

\section{Conteúdo de proteína bruta}

O conteúdo de proteína bruta (CPB) na matéria seca do capim-Tifton 85 foi influenciado pela interação entre tratamentos e cortes e o da aveia-preta, pelos tratamentos $(\mathrm{p}<0,01)$.

Com base no resultado dos testes de médias apresentados na Tabela 7, verifica-se que os teores de proteína bruta obtidos com a maior taxa de aplicação da ARB foram superiores aos da testemunha, para todos os cortes, em ambas as forrageiras. Com exceção do primeiro corte do Tifton 85, esses valores são superiores a 7,0 dag kg-1, considerado limite mínimo necessário pelos micro-organismos do rúmen para bovinos adultos (NRC, 1989).

Tabela 7. Conteúdo de proteína bruta $\left(\right.$ dag $\left.\mathrm{kg}^{-1}\right)$ das plantas utilizadas no experimento, em função das taxas de aplicação da ARB

\begin{tabular}{crrrrr}
\hline \multirow{2}{*}{ Corte } & \multicolumn{5}{c}{ Tratamentos } \\
\cline { 2 - 7 } & Testemunha & $\mathbf{2 5}$ & $\mathbf{5 0}$ & $\mathbf{7 5}$ & $\mathbf{1 0 0}$ \\
1 & $4,59 \mathrm{a}$ & $6,37 \mathrm{a}^{*}$ & $6,71 \mathrm{a}^{*}$ & $7,07 \mathrm{a}^{*}$ & $6,89 \mathrm{a}^{*}$ \\
2 & $6,78 \mathrm{~b}$ & $7,04 \mathrm{a}$ & $8,15 \mathrm{~b}^{*}$ & $7,35 \mathrm{a}$ & $8,35 \mathrm{~b}^{*}$ \\
3 & $9,47 \mathrm{c}$ & $10,46 \mathrm{~b}^{*}$ & $10,84 \mathrm{c}^{*}$ & $13,17 \mathrm{~b}^{*}$ & $13,80 \mathrm{c}^{*}$ \\
4 & $10,45 \mathrm{~d}$ & $10,74 \mathrm{~b}$ & $11,61 \mathrm{c}^{*}$ & $12,54 \mathrm{~b}^{*}$ & $14,75 \mathrm{~d}^{*}$ \\
\hline \multicolumn{5}{c}{ Aveia-preta } \\
Único & 6,36 & $9,20^{*}$ & $9,67^{*}$ & $10,68^{*}$ & $11,12^{*}$ \\
\hline
\end{tabular}

Valores seguidos de asterisco na linha diferem estatisticamente em nível de $5 \%$ de probabilidade da testemunha, pelo teste de Dunnett

Valores seguidos da mesma letra minúscula na coluna, não diferem estatisticamente em nível de $5 \%$ de probabilidade, pelo teste de Tukey

Os valores de CPB do capim-Tifton 85, referentes à máxima concentração da ARB, foram inferiores aos obtidos por Queiroz et al. (2001), que encontraram valores de 19,28 e 19,19 dag $\mathrm{kg}^{-1}$, nos primeiro e segundo cortes, respectivamente, aplicando água residuária de suinocultura, porém estão próximos aos obtidos por Rocha et al. (2003); Menegatti et al. (2002) e Ribeiro et al. (2000) que relatam valores variando de 5,0 a 15,0 dag $\mathrm{kg}^{-1}$.

Com relação à aveia-preta, em média os valores obtidos de CPB estão inferiores aos citados na literatura (Ferolla et al., 2008; Prado et al., 2006; Nakagawa \& Rosolem, 2005; Primavesi et al., 1999) e aos verificados por Matos et al. (2003), 14,53 dag kg-1 , usando água residuária da lavagem e despolpa de frutos do cafeeiro em rampas de tratamento; esta diferença pode ser devida à distinta composição das águas utilizadas e ao efeito de competição entre o Tifton 85 e a aveia-preta, no quarto ciclo de corte.

Considerando-se a média dos cortes para o Tifton 85 e o corte único da aveia-preta, a análise de regressão revela efeito linear positivo das taxas de aplicação da ARB sobre o conteúdo de proteína bruta (Tabelas 4 e 5); tal comportamento está coerente com o aporte de nutrientes propiciado pela ARB, principalmente $\mathrm{N}$, e com os resultados relatados para o Tifton 85 (Fonseca et al., 2007; Rocha et al., 2003; Menegatti et al., 2002) e aveia-preta (Lupatini et al., 
1998), resultados que indicam que a utilização da ARB em fertigação do Tiftons 85 e da aveia-preta pode contribuir para a melhoria do valor nutritivo dessas forrageiras.

\section{Composição mineral das gramíneas forrageiras}

O conteúdo de minerais no capim-Tifton 85 foi influenciado pela interação entre tratamentos e cortes $(p<0,01)$ e, na aveia-preta, pelos tratamentos $(\mathrm{p}<0,01)$. Os resultados dos testes de médias dessas variáveis, para ambas as forrageiras, estão apresentados nas Tabelas 8 e 9 e mostram diferenças significativas para todos os nutrientes avaliados entre a testemunha e a maioria dos tratamentos.

Observa-se, em todos os tratamentos que receberam ARB, que a concentração de $\mathrm{P}$ em ambas as forrageiras foi superior às obtidas na testemunha; para o capim-Tifton 85 houve tendência de aumento do teor de $\mathrm{P}$ nas plantas nos sucessivos cortes, o que pode ser explicado pelo efeito cumulativo no solo durante o período experimental.

Os teores médios de $\mathrm{P}$ do capim-Tifton 85 se encontram próximos aos relatados por Adeli et al. (2006), McLaughlin et al. (2004) e Ribeiro et al. (2000), porém menores que os encontrados nos trabalhos de McCullough et al. (2006), Abrahão (2006), Queiroz et al. (2004) e Oliveira et al.

Tabela 8. Concentração de minerais na matéria seca do capim-Tifton 85 para os diferentes cortes e taxas de aplicação da ARB

\begin{tabular}{|c|c|c|c|c|c|c|}
\hline \multirow{2}{*}{ Mineral } & \multirow{2}{*}{ Corte } & \multicolumn{5}{|c|}{ Tratamentos } \\
\hline & & Testemunha & 25 & 50 & 75 & 100 \\
\hline \multirow{4}{*}{$\begin{array}{c}P \\
\left(\operatorname{dag} \mathrm{kg}^{-1}\right)\end{array}$} & 1 & $0,13 \mathrm{a}$ & $0,17 a^{*}$ & $0,18 a^{*}$ & $0,19 a b^{*}$ & $0,18 a^{*}$ \\
\hline & 2 & $0,13 \mathrm{a}$ & $0,21 b^{*}$ & $0,18 a^{*}$ & $0,18 b^{*}$ & $0,22 b^{*}$ \\
\hline & 3 & $0,15 \mathrm{ab}$ & $0,23 b^{*}$ & $0,27 b^{*}$ & $0,28 c^{*}$ & $0,31 c^{*}$ \\
\hline & 4 & $0,19 \mathrm{~b}$ & $0,34 c^{*}$ & $0,33 c^{*}$ & $0,22 a b^{*}$ & $0,25 b^{*}$ \\
\hline \multirow{4}{*}{$\begin{array}{c}\mathrm{K} \\
\left(\operatorname{dag} \mathrm{kg}^{-1}\right)\end{array}$} & 1 & $1,62 \mathrm{a}$ & $1,64 \mathrm{a}$ & $1,84 \mathrm{a}^{*}$ & $1,76 \mathrm{a}$ & $1,88 \mathrm{a}^{*}$ \\
\hline & 2 & $1,73 \mathrm{a}$ & $1,62 \mathrm{a}$ & $1,71 \mathrm{a}$ & $1,80 \mathrm{a}$ & $1,87 \mathrm{a}$ \\
\hline & 3 & $1,77 \mathrm{a}$ & $1,55 a^{*}$ & $1,84 \mathrm{a}$ & $2,00 b^{*}$ & $2,07 b^{*}$ \\
\hline & 4 & $0,96 \mathrm{~b}$ & $1,05 \mathrm{~b}$ & $1,10 \mathrm{~b}$ & $1,12 c^{*}$ & $1,55 c^{*}$ \\
\hline \multirow{4}{*}{$\begin{array}{c}\mathrm{Ca} \\
\left(\operatorname{dag} \mathrm{kg}^{-1}\right)\end{array}$} & 1 & $0,20 \mathrm{a}$ & $0,33 \mathrm{a}^{\star}$ & $0,32 a^{*}$ & $0,29 \mathrm{a}^{*}$ & $0,32 \mathrm{a}^{*}$ \\
\hline & 2 & $0,38 \mathrm{~b}$ & $0,52 \mathrm{~b}$ * & $0,55 b c^{*}$ & $0,42 \mathrm{~b}$ & $0,44 \mathrm{abc}$ \\
\hline & 3 & $0,40 \mathrm{~b}$ & $0,56 b^{*}$ & $0,50 b c^{*}$ & $0,46 \mathrm{~b}$ & $0,45 \mathrm{bc}$ \\
\hline & 4 & $0,38 \mathrm{~b}$ & $0,57 b^{*}$ & $0,45 c^{*}$ & $0,45 b^{\star}$ & $0,38 a b$ \\
\hline \multirow{4}{*}{$\begin{array}{c}\mathrm{Mg} \\
\left(\operatorname{dag} \mathrm{kg}^{-1}\right)\end{array}$} & 1 & $0,14 \mathrm{a}$ & $0,13 \mathrm{a}$ & $0,13 \mathrm{a}$ & $0,13 \mathrm{a}$ & $0,15 \mathrm{a}$ \\
\hline & 2 & $0,18 \mathrm{~b}$ & $0,13 a^{*}$ & $0,12 a^{*}$ & $0,13 a^{*}$ & $0,14 a^{*}$ \\
\hline & 3 & $0,18 \mathrm{~b}$ & $0,15 b^{*}$ & $0,16 b^{*}$ & $0,17 \mathrm{~b}$ & $0,19 \mathrm{~b}$ \\
\hline & 4 & $0,03 \mathrm{c}$ & $0,07 c^{*}$ & $0,05 c^{*}$ & $0,04 \mathrm{c}$ & $0,05 c^{*}$ \\
\hline \multirow{4}{*}{$\begin{array}{c}\mathrm{Na} \\
\left(\operatorname{dag} \mathrm{kg}^{-1}\right)\end{array}$} & 1 & $0,03 \mathrm{a}$ & $0,03 \mathrm{a}$ & $0,03 \mathrm{a}$ & $0,03 \mathrm{a}$ & $0,03 \mathrm{a}$ \\
\hline & 2 & $0,03 \mathrm{a}$ & $0,03 \mathrm{a}$ & $0,03 \mathrm{a}$ & $0,03 \mathrm{a}$ & $0,03 \mathrm{a}$ \\
\hline & 3 & $0,02 \mathrm{a}$ & $0,03 a^{*}$ & $0,03 a^{*}$ & $0,04 a^{\star}$ & $0,04 a^{\star}$ \\
\hline & 4 & $0,06 \mathrm{~b}$ & $0,10 b^{*}$ & $0,06 \mathrm{~b}$ & $0,04 a^{*}$ & $0,05 \mathrm{a}^{*}$ \\
\hline \multirow{4}{*}{$\begin{array}{c}\mathrm{Cu} \\
\left(\mathrm{mg} \mathrm{kg}^{-1}\right)\end{array}$} & 1 & $9,09 \mathrm{a}$ & $10,06 \mathrm{a}$ & $8,63 \mathrm{a}$ & $8,10 \mathrm{a}$ & $8,81 \mathrm{a}$ \\
\hline & 2 & $9,92 \mathrm{a}$ & $11,35 \mathrm{a}$ & $12,03 b^{*}$ & $10,49 \mathrm{~b}$ & $11,69 b^{*}$ \\
\hline & 3 & $9,27 \mathrm{a}$ & $10,54 \mathrm{a}$ & $11,41 b^{*}$ & $12,77 c^{*}$ & $13,29 c^{*}$ \\
\hline & 4 & $0,77 \mathrm{~b}$ & $1,91 \mathrm{~b}$ & $0,95 \mathrm{c}$ & $0,87 \mathrm{~d}$ & $1,39 \mathrm{~d}$ \\
\hline \multirow{4}{*}{$\begin{array}{c}\mathrm{Zn} \\
\left.(\mathrm{mg} \mathrm{kg})^{-1}\right)\end{array}$} & 1 & $39,66 a b$ & $44,48 \mathrm{~b}$ & $41,82 \mathrm{ab}$ & $34,66 \mathrm{c}$ & $33,25 c^{*}$ \\
\hline & 2 & $35,83 \mathrm{a}$ & 39,96 b & $40,88 \mathrm{~b}$ & $41,30 b^{*}$ & $43,27 b^{*}$ \\
\hline & 3 & $41,26 \mathrm{~b}$ & $53,23 a^{*}$ & $46,19 \mathrm{a}$ & $48,80 a^{*}$ & $50,09 \mathrm{a}^{*}$ \\
\hline & 4 & $0,43 \mathrm{c}$ & $2,64 \mathrm{c}$ & $0,92 \mathrm{c}$ & $0,53 \mathrm{~d}$ & $1,17 \mathrm{~d}$ \\
\hline
\end{tabular}

Valores seguidos de asterisco na linha, diferem estatisticamente em nível de $5 \%$ de probabilidade da testemunha, pelo teste de Dunnett

Valores seguidos da mesma letra minúscula na coluna, não diferem estatisticamente em nível de $5 \%$ de probabilidade, pelo teste de Tukey, para cada mineral
Tabela 9. Concentração de minerais na matéria seca da aveia-preta, em função das taxas de aplicação da ARB

\begin{tabular}{|c|c|c|c|c|c|}
\hline \multirow{2}{*}{ Mineral } & \multicolumn{5}{|c|}{ Tratamentos } \\
\hline & Testemunha & 25 & 50 & 75 & 100 \\
\hline \multirow{5}{*}{ dag $\mathrm{kg}^{-1}$} & 0,20 & $0,32^{*}$ & $0,34^{*}$ & $0,38^{*}$ & $0,35^{*}$ \\
\hline & 0,76 & $1,62^{*}$ & $1,78^{*}$ & 2,03 * & $2,22^{*}$ \\
\hline & 0,35 & $0,48^{*}$ & $0,44^{*}$ & $0,47^{*}$ & $0,48^{*}$ \\
\hline & 0,02 & $0,07^{*}$ & $0,06^{*}$ & $0,07^{*}$ & $0,07^{*}$ \\
\hline & 0,23 & $0,16^{*}$ & 0,19 * & 0,22 & $0,33^{*}$ \\
\hline \multirow{2}{*}{$\mathrm{mg} \mathrm{kg}^{-1}$} & 1,73 & $2,68^{*}$ & 2,03 & $2,34^{*}$ & 1,90 \\
\hline & 0,44 & $2,43^{*}$ & $2,27^{*}$ & $2,12^{*}$ & 2,30 * \\
\hline
\end{tabular}

Valores seguidos de asterisco na linha, diferem estatisticamente em nível de $5 \%$ de probabilidade da testemunha, pelo teste de Dunnett

(2000); já para a aveia-preta esses teores estão superiores aos encontrados por McDonald \& Wilson (1980), Primavesi et al. (1999), Santi et al. (2003), Matos et al. (2005) e Prado et al. (2006).

Do ponto de vista nutricional, apenas os tratamentos 75 e 100 do terceiro corte e 25 e 50 do quarto corte do Tifton 85 , apresentaram teores de $\mathrm{P}$ que atenderiam às exigências de vacas leiteiras com $400 \mathrm{~kg}$ de peso vivo e produção variando de 7 a $20 \mathrm{~kg}$ de leite por dia $(0,28$ a 0,37 dag kg-1) de $\mathrm{P}$ na matéria seca (NRC, 1989), enquanto para a aveia-preta os resultados são satisfatórios.

Os modelos de regressão para teor de fósforo em função das taxas de aplicação da ARB, para o capim-Tifton 85 e a aveia-preta, não apresentaram significância estatística indicando que, em ambas as forrageiras, os teores de P na matéria seca não foram influenciados pelas taxas de aplicação da ARB, comportamento também observado por (Krzywy \& Woloszyk, 1984) e grama bermuda (Adeli et al., 2006).

$\mathrm{O}$ resultado do teste de médias indica redução significativa no teor de $\mathrm{K}$ nas plantas do capim-Tifton 85, no quarto corte, em todos os tratamentos (Tabela 8); tal comportamento demonstra que o efeito da competição entre as duas forrageiras foi maior que o efeito cumulativo no solo causado pelo aporte desse nutriente; por outro lado, os teores de $\mathrm{K}$ nas plantas de aveia-preta (Tabela 9) apresentaram valores superiores relativamente ao Tifton 85, indicando maior competitividade da aveia.

Em todos os tratamentos as forrageiras apresentaram teores de $\mathrm{K}$ superiores a $0,90 \mathrm{dag}_{\mathrm{kg}}{ }^{-1}$, indicados pelo NRC (1989) como desejável para vacas leiteiras com 400 kg de peso vivo, produzindo de 7 a 20 quilos de leite por dia; para o capim-Tifton 85, os teores obtidos são inferiores aos encontrados por Oliveira et al. (2000); Queiroz et al. (2001); McLaughlin et al. (2004) e Adeli et al. (2006); porém são superiores aos relatados nos trabalhos de Ribeiro et al. (2000) e McCullough et al (2006) e semelhantes aos obtidos por Abrahão (2006); já para a aveia-preta esses teores estão inferiores aos relatados por Matos et al. (2005) mas dentro do intervalo encontrado por Santi et al. (2003) e Prado et al. (2006), no que pese a aveia ter sido cultivada em sistema de consórcio.

A análise de regressão demonstra efeito linear positivo ( $\mathrm{p}<0,01)$ das taxas de aplicação da ARB sobre os teores de $\mathrm{K}$, em ambas as forrageiras (Tabelas 4 e 5), a aveia-preta, 
porém, apresentou resposta mais intensa para esta variável, confirmando ser mais competitiva na absorção de K, quando comparada com o capim-Tifton 85.

Os tratamentos que receberam ARB indicaram teores de Ca superiores aos da testemunha, em ambas as forrageiras (Tabelas 8 e 9); observa-se, também, tendência de aumento nos teores de Ca no capim-Tifton 85, do primeiro para o quarto corte em todos os tratamentos, sugerindo o efeito cumulativo deste nutriente no solo; não se observa, entretanto, efeito de competição pelo cálcio no quarto corte, entre as forrageiras.

Quanto à nutrição animal, todos os tratamentos com utilização de ARB no cultivo da aveia-preta mostraram teores de Ca entre 0,43 e 0,58 dag $\mathrm{kg}^{-1}$, considerado bom (NRC, 1989); no entanto, para o Tifton 85 apenas a partir do segundo corte essas exigências foram satisfeitas. No geral, os teores obtidos para esse capim estão semelhantes aos relatados em diversos trabalhos (Adeli et al., 2006; Queiroz et al., 2001; Oliveira et al., 2000; Ribeiro et al., 2000; Martin, 1997), porém superiores aos encontrados por McCullough et al. (2006); enquanto para a aveia-preta esses teores são inferiores aos obtidos por Matos et al. (2005) e se assemelham aos encontrados por Prado et al. (2006), Santi et al. (2003) e McDonald \& Wilson (1980).

A análise de regressão demonstra efeito linear negativo das taxas de aplicação da ARB sobre os teores de Ca para o Tifton 85, conforme observado na equação ajustada apresentada na Tabela 4. Resultados semelhantes, mostrando decréscimo no teor de Ca em plantas de grama-bermuda decorrente da aplicação de matéria orgânica, N e K, têm sido relatados (Adeli et al., 2006; Martim; 1997) e podem estar relacionados com as crescentes concentrações de $\mathrm{K}$ no solo que, por competição, reduz a absorção de Ca pelo Tifton 85 (Soder \& Stout, 2003). Os teores de Ca para a aveia preta não se ajustaram aos modelos testados ( $\hat{Y}=0,469)$.

Observa-se, na Tabela 8, para o capim-Tifton 85, que apenas no quarto corte os tratamentos com ARB apresentaram teores de Mg superiores aos obtidos na testemunha ocorrendo sensível redução desse elemento em relação aos cortes anteriores; para a aveia-preta, os teores de Mg de todos os tratamentos foram superiores aos da testemunha apresentando, porém, valores relativamente baixos (Tabela 9). A redução dos teores de $\mathrm{Mg}$ no quarto corte é consequente da ausência desse nutriente na ARB.

Excetuando-se o quarto corte, os teores de Mg obtidos neste trabalho para o capim-Tifton 85, estão próximos aos encontrados por McLaughlin et al. (2004) e Queiroz et al. (2001) e inferiores aos relatados por Adeli et al. (2006); McCullough et al. (2006); Oliveira et al. (2000) e Martin (1997); já para a aveia-preta os teores de Mg encontrados são superiores aos obtidos por Santi et al. (2003) e inferiores àqueles verificados nos trabalhos de McDonald \& Wilson (1980), Matos et al. (2005) e Prado et al. (2006).

Os modelos de regressão para teor de magnésio em função das taxas de aplicação da ARB, para o capim-Tifton 85 e a aveia-preta, não apresentaram significância estatística; em referência ao cálcio, decréscimos nos teores de Mg para gramíneas do gênero Cynodon já foram observados (Adeli et al., 2006; Martin, 1997) comportamento que se justifica pela alta relação K:Mg no solo, visto que o excesso de K pode reduzir a absorção do $\mathrm{Mg}$ (Malavolta, 1981).

Os tratamentos com ARB apresentaram teores de sódio superiores aos obtidos na testemunha apenas no terceiro corte do Tifton 85 (Tabela 8), enquanto no quarto corte se nota aumento significativo desse nutriente em relação aos anteriores devido, provavelmente, ao efeito cumulativo no solo; para a aveia-preta (Tabela 9) somente o tratamento correspondente à maior taxa de aplicação proporcionou concentração superior à obtida na testemunha, porém em todos eles os teores de Na estão bem superiores aos obtidos no Tifton 85, demonstrando que esta forrageira apresentou maior absorção de sódio. Ayers \& Westcot (1999) classificam a aveia como forrageira moderadamente sensível à salinidade e semitolerante ao sódio trocável e as gramíneas do gênero $C y$ nodon são consideradas tolerantes.

Korndörfer (2006) relata que a concentração de sódio nas plantas pode variar de 0,0013 a 3,51 dag kg-1, sendo considerado elemento benéfico para muitas espécies, principalmente plantas com metabolismo $\mathrm{C}_{4}$ e MAC (metabolismo ácido das crassuláceas). De acordo com Mengel \& Kirkby (2001), o sódio está envolvido na regeneração do fosfoenolpiruvato em plantas $\mathrm{C}_{4}$ e MAC, podendo substituir o potássio em algumas funções.

Os teores de sódio encontrados no presente trabalho para o capim-Tifton 85, estão próximos aos obtidos por Abrahão (2006) e Queiroz et al. (2001) e, para a aveia-preta, são inferiores aos relatados por McDonald \& Wilson (1980), que obtiveram teores variando de 0,30 a 0,48 dag $\mathrm{kg}^{-1}$ embora superiores aos 0,048 dag kg-1 obtidos por Matos et al. (2005).

Observa-se efeito quadrático das taxas de aplicação da ARB sobre os teores de sódio em ambas as forrageiras (Tabelas 4 e 5), estimando-se valores mínimos de 0,159 e 0,035 dag kg-1 , nas taxas de aplicação de 36,7 e 80,0 $\mathrm{kg} \mathrm{ha}^{-1}$ de $\mathrm{K}$ na ARB, para a aveia-preta e o capim-Tifton 85, respectivamente; esses resultados confirmam a tolerância do Tifton 85 aos efeitos do sódio trocável.

Na Tabela 8 se observa forte redução nos teores desses elementos no quarto corte, que pode ser devida à diminuição do aporte propiciado pela ARB, observada a partir do terceiro ciclo (Tabela 1) e, em virtude da competição com a aveia-preta, no quarto ciclo. Excetuando-se o quarto corte, os teores de cobre e zinco obtidos para o Tifton 85 estão próximos aos relatados por Queiroz et al. (2001) e superiores aos observados por McLaughlin et al. (2004), ambos utilizando água residuária de suinocultura porém estão inferiores aos valores relatados por McCullough et al. (2006) que encontraram variações de 14 a $29 \mathrm{mg} \mathrm{kg}^{-1}$ para o cobre e 46 a $59 \mathrm{mg} \mathrm{kg}^{-1}$ para o zinco. Dechen \& Nachtigall (2006), consideram que as concentrações médias de $\mathrm{Cu}$ e $\mathrm{Zn}$ nas plantas variam de 5-20 e 20-50 mg kg-1 de matéria seca, respectivamente.

Para a aveia-preta a concentração de $\mathrm{Cu}$ no tecido vegetal do tratamento correspondente à maior taxa de aplicação não foi superior à da testemunha; no caso do zinco, todos os tratamentos apresentaram teores superiores aos da testemunha; em geral, os teores obtidos estão inferiores aos relatados por McDonald \& Wilson (1980) e Primavesi et al. (1999). 
Observou-se efeito linear negativo das taxas de aplicação da ARB sobre os teores de cobre na aveia-preta (Tabela 5), enquanto no caso do capim-Tifton 85 os modelos testados não indicaram significância estatística; por outro lado, os teores de zinco no capim-Tifton 85 se ajustaram a um modelo quadrático (Tabela 4), estimando-se valor mínimo de 31,3 dag kg-1 para a dose de 78,84 kg ha-1 de K na ARB; já para a aveia-preta não se constatou efeito das taxas de aplicação da ARB sobre o teor de zinco no tecido vegetal.

\section{CONCLUSÕES}

As crescentes taxas de aplicação da água residuária de bovinocultura utilizadas sob forma de fertigação, calculadas com base na concentração de potássio, apresentaram as seguintes consequências:

1. Não reduzem a taxa fotossintética, a taxa transpiratória nem a condutância estomática do capim-Tifton 85 e da aveia-preta.

2. Aumentam os valores de leitura SPAD indicando maior teor de clorofila na folha das plantas do capim-Tifton 85 e de aveia-preta.

3. Aumentam o rendimento forrageiro, o conteúdo de proteína bruta e os teores de $\mathrm{K}, \mathrm{Mg}$ e Na na Tifton 85 e de $\mathrm{P}$ e $\mathrm{K}$ na aveia-preta.

4. Reduzem os teores de Ca e Zn na Tifton 85 e de Na e $\mathrm{Cu}$ na aveia-preta.

5. Não influenciam os teores de $\mathrm{P}$ e Cu na Tifton 85 nem de $\mathrm{Ca}, \mathrm{Mg}$ e Zn na aveia-preta.

\section{AGRADECIMENTOS}

Ao CNPq, pelo apoio financeiro à pesquisa.

\section{LITERATURA CITADA}

Abrahão, S. S. Tratamento de água residuária de laticínios em sistemas alagados construídos cultivados com forrageira. Viçosa: UFV, 2006. 110p. Dissertação Mestrado

Adekalu, K. O.; Okunade, D. A. Effects of pond water and sewage effluent treatments on yield and nutrient uptake of maize (Zea mays L.). Tropical Agriculture, v.79, p.120-124, 2002.

Adeli, A.; Rowe, D. E.; Reaf, J. J. Effects of soil type on bermudagrass response to broiler litter application. Agronomy Journal, v.98, p.148-155, 2006.

Ayers, R. S.; Westcot, D. W. A qualidade da água na agricultura. Campina Grande: UFPB, 1999. 153p.

Bullock, D. G.; Anderson, D. S. Evaluation of the minolta SPAD-502 clorophyll meter for nitrogen management in corn. Journal of the Plant Nutrition, v.21, n.4, p.741-755, 1998.

CFSEMG - Comissão de Fertilidade do Solo do Estado de Minas Gerais. Recomendação para uso de corretivos e fertilizantes em Minas Gerais. 5a. aproximação. Viçosa: CFSEMG, 1999. 359p.
Chen, K.; Hu, G.; Keutgen, N.; Janssens, M. J. J.; Lenz, F. Effects of $\mathrm{NaCl}$ salinity and $\mathrm{CO} 2$ enrichment on pepino (Solanum muricatum Ait.) II. Leaf photosynthetic properties and gas exchange. Scientia Horticulturae, v.81, p.43-56, 1999.

Dechen, A. R.; Nachtigall, G. R. Micronutrientes. In: Fernandes, M. S. (ed.). Nutrição Mineral de Plantas. Viçosa: SBCS, 2006. p.328-354.

Ferolla, F. S.; Vásquez, H. M.; Da Silva, J. F. C.; Viana, A. P.; Domingues, F. N.; Lista, F. N. Composição bromatológica e fracionamento de carboidratos e proteínas de aveia-preta e triticale sob corte e pastejo. Revista Brasileira de Zootecnia, v.37, n.2, p.197-204, 2008.

Fonseca, A. F.; Melfi, A. J.; Monteiro, F. A.; Montes, C. R.; Almeida, V. V.; Herpin, U. Treated sewage effluent as a source of water and nitrogen for Tifton 85 bermudagrass. Agricultural Water Management, v.87, p.328-336, 2007.

Grattan, S. R.; Grieve, C. M.; Poss, J. A.; Robinson, P. H.; Suarez, D. L.; Benes, S. E. Evaluation of salt-tolerant forages for sequential water reuse systems. I. Biomass production. Agricultural Water Management, v.70, p.109-120, 2004.

Korndörfer, G. H. Elementos benéficos. In: Fernandes, M. S. (ed.). Nutrição mineral de plantas. Viçosa: SBCS, 2006. p.355-374.

Krzywy, E.; Woloszyk, C. Effect of increasing rates of nitrogen fertilizer on yeld and chemical composition of oats. Zeszyty Naukowe Akademii Rolniczej w Szczecinie, v.35, p.151-158, 1984.

Larcher, W. Ecofisiologia vegetal. São Carlos: RiMa Artes e Textos, 2000. 531p.

Lupatini, G. C.; Restle J.; Ceretta, M.; Moojen, E. L.; Bartz, H. R. Avaliação da mistura de aveia preta e azevém sob pastejo submetida a níveis de nitrogênio. Pesquisa Agropecuária Brasileira, v.33, n.11, p.1939-1943, 1998.

Lutts, S.; Kinet, J. M.; Bouharmont, J. NaCl-induced senescence in leaves of rice (Oryza sativa L.) cultivars diaering in salinity resistance. Annals of Botany, n.78, p.389-398, 1996.

Malavolta, E. Manual de química agrícola. São Paulo: Agronômica Ceres, 1981. 596p.

Martim, R. A. Doses de nitrogênio e potássio para produção, composição e digestibilidade dos capins Coastcross 1 e Tifton 85 em um Latossolo Vermelho-Amarelo. Piracicaba: ESALQ USP, 1997. 109p. Dissertação Mestrado

Matos, A. T.; Pinto, A. B.; Pereira, O. G.; Soares, A. A.; Barros, F. M. Extração de nutrientes por forrageiras cultivadas com água residuária do beneficiamento dos frutos do cafeeiro. Revista Ceres, v.53, n.303, p.675-688, 2005.

Matos, A. T.; Pinto, A. B.; Pereira, O. G.; Soares, A. A.; Lo Monaco, P.A. Produtividade de forrageiras utilizadas em rampas de tratamento de águas residuárias da lavagem e despolpa dos frutos do cafeeiro. Revista Brasileira de Engenharia Agrícola e Ambiental, v.7, n.1, p.154-158, 2003.

McCullough, P. E.; Liu, H.; Mccarty, L. B.; Whitwell, T.; Toler, J. E. Bermudagrass putting green growth, color, and nutrient partitioning influenced by nitrogen and trinexapac-ethyl. Crop Science, v.46, p.1515-1525, 2006.

McDonald, R. C.; Wilson, K. R. Dry matter yields, digestibilities, mineral levels, and cattle growth rates on greenfeed oats at different stages of development. New Zealand Journal of Experimental Agriculture, v.8, p.105-109, 1980. 
Mclaughlin, M. R.; Farbrother, T. E.; Rowe, D. E. Nutrient uptake by warm-season perennial grasses in a swine effluent spray field. Agronomy Journal, v.96, p.484-493, 2004.

Menegatti, D. P.; Rocha, G. P.; Furtini Neto, A. E.; Muniz, J. A. Nitrogênio na produção de matéria seca, teor e rendimento de proteína bruta de três gramíneas do gênero cynodon. Ciência e Agrotecnologia, v.26, n.3, p.633-642, 2002.

Mengel, K.; Kirkby, E.A. Principles of plant nutrition. 5.ed. Worblauden-Bern, Switezland: International Potash Institute, 2001. 849p.

Mohammad, M. J.; Ayadi, M. Forage yield and nutrient uptake as influenced by secondary treated wastewater. Journal of Plant Nutrition, v.27, p.351-364, 2004.

Nakagawa, J.; Rosolem, C. A. Teores de nutrientes na folha e nos grãos de aveia-preta em função da adubação com fósforo e potássio. Bragantia, v.64, n.3, p.441-445, 2005.

NRC - National Research Council. Nutrient requirements of dairy cattle. 6.ed., Washington: National Academy Press, 1989. 157p.

Oliveira, M. A.; Pereira, O. G.; Garcia, R.; Obeid, J. A.; Cecon, P. R.; Moraes, S. A.; Silveira, P. R. Rendimento e valor nutritivo do capim tifton 85 (Cynodon spp.) em diferentes idades de rebrota. Revista Brasileira de Zootecnia, v.29, n.6, p.1949-1960, 2000.

Parida, A. K.; Bandhu, A. Salt tolerance and salinity effects on plants: a review. Ecotoxicology and Environmental Safety, v.60, n.3, p.324-349, 2005.

Prado, R. M.; Romualdo, L. M.; Vale, D. W. Resposta da aveia preta à aplicação de fósforo sob duas doses de nitrogênio em condições de casa de vegetação. Acta Scientiarum. Agronomy, v.28, n.4, p.527-533, 2006.

Premazzi, L.; Monteiro, F. A.; Corrente, J.E. Tillering of tifton 85 bermudagrass in response to nitrogen rates and time of application after cutting. Scientia Agricola, v.60, n.3, p.565-571, 2003.

Primavesi, A. C.; Primavesi, O.; Godoy, R. Nutrient uptake and nutritional efficiency of oat cultivars in relation to nitrogen and cutting intensities. Scientia Agricola, v.56, n.3, p.613-620, 1999.
Queiroz, F. M.; Matos, A. T.; Pereira, O. G. ; Oliveira, R. A. The dry matter yield of forage-grass species in overland flow treatment using swine wastewater. In: Soares, A. A.; Saturnino, H. M. (Org.). Enviroment and the water: Competitive use and conservation strategies for water and natural resources. Brasíla: ABID, 2001. p.166-172.

Queiroz, F. M.; Matos, A. T.; Pereira, O. G.; Oliveira, R. A.; Lemos, A. F. Características químicas do solo e absorção de nutrientes por gramíneas em rampas de tratamento de águas residuárias da suinocultura. Engenharia na Agricultura, v.12, p.77-90, 2004.

Ribeiro, K. G.; Pereira, O. G.; Garcia, R.; Valadares Filho, S. C.; Cecon, P. R. Composição e extração mineral do capim-tifton 85, em três idades de rebrota, sob cinco doses de nitrogênio. In: Reunião Anual da Sociedade Brasileira de Zootecnia, 37, 2000, Viçosa. Anais... Viçosa: SBZ, 2000. p.55-55.

Rocha, G. P., Evangelista, A. R.; Lima, J. A. Nitrogênio na produção de matéria seca, teor e rendimento de proteína bruta de gramíneas tropicais. Pasturas Tropicales, v.22, n.1, p.67-73, 2003.

Rosa-Ibarra, M. de La; Maiti, R. K. Biochemical mechanism in glossy sorghum lines for resistance to salinity stress. Plant Physiology, v.146, p.515-519, 1995.

Santi, A.; Amado, T. J. C.; Costa, J. A. A. Adubação nitrogenada na aveia preta. I - Influência na produção de matéria seca e ciclagem de nutrientes sob sistema de plantio direto. Revista Brasileira de Ciência do Solo, v.27, p.1075-1083, 2003.

Silva, D. J.; Queiroz, A. C. Análise de alimentos (métodos químicos e biológicos). 3.ed. Viçosa: UFV, 2002. 235p.

Soder, K. J.; Stout, W. L. Effect of soil type and fertilization level on mineral concentration of pasture: Potential relationships to ruminant performance and health. Journal of Animal Science, v.81, p.1603-1610, 2003.

Taiz, L.; Zeiger, E. Fisiologia vegetal. $3^{\mathrm{a}}$ ed. Porto Alegre: Artmed. 2004. 719p. 